\title{
Management of Operation Iraqi Freedom and Operation Enduring Freedom veterans in a Veterans Health Administration chiropractic clinic: A case series
}

\author{
Anthony J. Lisi, DC \\ Department of Veterans Affairs Connecticut Healthcare System, West Haven, CT; University of Bridgeport College of \\ Chiropractic, Bridgeport, $C T$
}

\begin{abstract}
Operation Iraqi Freedom/Operation Enduring Freedom (OIF/OEF) veterans commonly seek care for musculoskeletal complaints in Veterans Health Administration (VHA) facilities. Chiropractic services for musculoskeletal conditions have recently been introduced to VHA. No reports have been published on chiropractic care for OIF/OEF veterans. This study was designed to describe elements of the processes and outcomes of care for OIF/OEF veterans in a VHA chiropractic clinic. A retrospective review of consecutive cases consulted to one VHA chiropractic clinic was conducted. Thirty-one cases were identified. Consultations originated in primary care and specialty clinics that commonly manage musculoskeletal conditions. Military traumatic injury and posttraumatic stress disorder were common. Adverse effects of treatment were mild and transitory. In 19 cases (61\%), a pain decrease above the threshold for minimally important change was reported. This article is the first description of health services delivered to OIF/OEF veterans in a VHA chiropractic clinic. Chiropractic management was safe in these cases, and results support the hypothesis that such management may be effective in certain OIF/OIF veterans. A better understanding of the characteristics of these particular patients and the processes of care received in VHA chiropractic clinics is needed to improve the clinical care of these veterans.
\end{abstract}

Key words: Afghanistan, chiropractic, health services, Iraq war, physical medicine, providers, rehabilitation, systems integration, veterans, Veterans Health Administration.

\section{BACKGROUND}

Operation Iraqi Freedom/Operation Enduring Freedom (OIF/OEF) veterans are a priority population for the Veterans Health Administration (VHA) [1]. From October 2001 through December 2008, approximately 981,834 OIF/OEF veterans have left Active Duty and become eligible for VHA benefits and services [2]. Reports depict that 498,737 OIF/OEF veterans received VHA benefits and services in fiscal year (FY) 2008 [3] and approximately 425,538 have received VHA healthcare [2]. The two most frequent diagnoses seen in this group are musculoskeletal system and connective tissue disorders (International Classification of Diseases-10th

Abbreviations: $\mathrm{CPT}=$ Current Procedural Terminology, FY = fiscal year, ICD-10 = International Classification of Diseases10th Edition, NRS = numerical rating scale, OIF/OEF = Operation Iraqi Freedom/Operation Enduring Freedom, PTSD = posttraumatic stress disorder, VACHS $=$ Department of Veterans Affairs Connecticut Healthcare System, VHA = Veterans Health Administration.

Address all correspondence to Anthony J. Lisi, DC; Chiropractic Service, VA Connecticut Healthcare System, 950 Campbell Avenue, Building 2, 4th Floor East, West Haven, CT 06516; 203-932-5711; fax: 203-937-4984.

Email: Anthony.lisi@va.gov

DOI:10.1682/JRRD.2009.07.0095 
Edition [ICD-10] 710-739; seen in 50.0\% of cases) and mental disorders (ICD-10 290-319; seen in $45.6 \%$ of cases) [2]. Multiple diagnoses per individual are common.

Chiropractic services are a novel introduction to VHA [4]. In response to Public Law 107-135, VHA established chiropractic clinics at 26 facilities beginning late 2004. Without further mandate, from FY2005 to FY2008, the number of clinics increased from 26 to 36 (38\%) and the number of veterans seen at these clinics increased from more than 4,000 to more than 13,000 (225\%).

As specified by VHA Directive 2004-035, VHA provides chiropractic services for management of musculoskeletal conditions. Current evidence suggests that spinal manipulation, a central component of chiropractic treatment, may provide benefit in some cases of low back and neck pain [5-6].

Since spinal pain complaints are common in OIF/ OEF veterans [7-8], some of these patients are likely receiving care at VHA chiropractic clinics. However, no data have been published on chiropractic services for OIF/OEF veterans. Furthermore, since these patients have not been represented in previous clinical trials of spinal manipulation and may have unique health needs, the role of chiropractic management in such cases is unknown.

Given that OIF/OEF veterans are a priority population for VHA and that chiropractic care is a novel introduction to VHA's services, an understanding of the intersection of these two phenomena may be of interest. Thus, the purpose of this study is to describe select processes and outcomes of care for a group of OIF/OEF veterans seen at one VHA chiropractic clinic.

\section{METHODS}

This study is a retrospective review of consecutive cases. An administrative specialist searched the Department of Veterans Affairs Connecticut Healthcare System's (VACHS's) electronic scheduling database to identify all new patient consultations to the VACHS chiropractic clinic over a 6-month period (November 1, 2007, to April 30, 2008). This date range was chosen so that the most recent case included would have initiated care at least 3 months before the start of this study (August 1, 2008). A research assistant cross-referenced this list with the Computerized Patient Record System to identify the subset of OIF/OEF veterans. I verified the OIF/OEF status of the cases and performed the data extraction and analysis. All cases that completed consultation and at least one follow-up visit were included.

All patients received usual and customary chiropractic management as typically delivered at the VACHS clinic; no experimental protocol was used.

This study describes the following features of the included cases:

1. Patient pretreatment characteristics.

a. Demographics.

-Age.

-Sex.

-Consulting service.

b. Clinical presentation.

-Reason for seeking care.

-Duration of complaint.

- Mechanism of onset.

-Pain intensity at presentation.

-Prior treatment.

-Comorbid posttraumatic stress disorder (PTSD).

2. Elements of chiropractic management.

a. Examination procedures and findings.

b. Interventions.

3. Outcomes.

a. Adverse events.

b. Change in pain intensity.

c. Case disposition.

Pain intensity was measured via the 11-point numerical rating scale (NRS) [9], with a predetermined minimum clinically important difference of 2 points [10]. Adverse events were assessed via patient subjective report.

Data from these cases were entered into a spreadsheet (Microsoft Excel, Microsoft Corp.; Redmond, Washington) for analysis.

\section{RESULTS}

The chart review identified 31 OIF/OEF veterans consulted to the clinic over the 6-month study period. All these cases completed an initial consultation and at least one follow-up visit; thus, this study reports on all consecutive veterans consulted to the clinic during the study period. 


\section{Demographics}

The average patient age was 28.5 years (range 19 to 47 years). Twenty-five (81\%) were male and six (19\%) were female. The most common consulting service was primary care (48\%), followed by physiatry (26\%), urgent care/emergency department (10\%), rheumatology (10\%), and neurology (6\%).

\section{Clinical Presentation}

Characteristics of the patients' chief complaints are listed in Table 1. The most common reasons for seeking chiropractic care were low back pain with or without leg pain (48\%) and mid back (thoracic) pain (32\%).

Patients reported that duration of complaint was on average 14 months (range 2 to 72 months). Onset of pain as a result of military trauma was reported by 19 patients; of these, 12 sustained blast injuries/polytrauma and 6 of those 12 were diagnosed with traumatic brain injury.

Median baseline pain intensity reported on the NRS was 7 (mean 6.5, range 4 to 9). All cases underwent some prior treatment for the chief complaint, with the most common treatment being nonsteroidal anti-inflammatory drugs (100\%), muscle relaxants (65\%), and physical therapy (61\%).

\section{Table 1.}

Clinical presentation of 31 OIF/OEF veterans consulted to VHA chiropractic clinic.

\begin{tabular}{lcc}
\hline \multicolumn{1}{c}{ Clinical Characteristic } & Cases (n) & Mean (\%) \\
\hline Chief Complaint & 10 & 32 \\
LBP without leg pain/deficit & 10 & 32 \\
Thoracic pain & 5 & 16 \\
LBP with leg pain/deficit & 3 & 10 \\
Neck pain without arm pain/deficit & 1 & 3 \\
Neck pain with arm pain/deficit & 1 & 3 \\
Headache & 1 & 3 \\
Shoulder pain & & \\
Prior Treatment & 31 & 100 \\
NSAIDs & 20 & 65 \\
Muscle relaxants & 19 & 61 \\
Physical therapy & 12 & 39 \\
Opioid analgesics & 5 & 16 \\
Trigger point injection & 4 & 13 \\
Chiropractic treatment & 4 & 13 \\
Acupuncture & 4 & 13 \\
Massage & 3 & 10 \\
Epidural steroid injection & 2 & 6 \\
Botulinum toxin injection & 1 & 3 \\
Facet block & \multicolumn{2}{c}{. } \\
\hline LBP = low back pain, NSAID = nonsteroidal anti-inflammatory drug, OIF/ \\
OEF = Operation Iraqi Freedom/Operation Enduring Freedom, VHA = Veter- \\
ans Health Administration. & & \\
\hline \hline
\end{tabular}

\section{Posttraumatic Stress Disorder}

Twenty-one cases (68\%) screened positive for PTSD in primary care before consultation. Of these, 16 were currently or previously being followed in mental health clinics and 5 had declined mental health treatment. During the course of management, 3 of the 10 veterans with initially negative PTSD screens exhibited PTSD symptomatology and were screened positive by the chiropractic clinic. Screening was performed via the 4-item Primary Care PTSD Screen with a cutoff score of 2 for increased sensitivity [11].

\section{Clinical Services}

All cases (100\%) underwent complete history and various physical examination procedures, including standard orthopedic and neurological testing. The level of evaluation and management service at consultation was "Expanded Problem Focused" (Current Procedural Terminology ${ }^{\circledR}\left[\mathrm{CPT}^{\circledR}\right]$ 99242) in 20 cases (65\%) and "Problem Focused” (CPT 99241) in 11 cases (35\%).

Interventions are reported in Table 2. All 31 cases (100\%) received education on natural history and self-care, manual spinal manipulation, and therapeutic exercise. In 23 cases (74\%), physical modalities and manual myofascial release were used. Patients were seen for an average of 6.1 visits (median 6, range 2 to 19). Treatment duration was pragmatically determined by reported outcome. The trial was ended when patients reported resolution of pain ( $0 / 10$ on the NRS) or no pain decrease over two to four consecutive visits.

Table 2.

Intervention usage by $31 \mathrm{OIF} / \mathrm{OEF}$ veterans consulted to VHA chiropractic clinic.

\begin{tabular}{|c|c|c|}
\hline Intervention & Cases (n) & Mean (\%) \\
\hline Education/Self-Care & 31 & 100 \\
\hline Exercise & 31 & 100 \\
\hline Manual Spinal Manipulation* & 31 & 100 \\
\hline Manual Myofascial Release & 23 & 74 \\
\hline Physical Modalities & 23 & 74 \\
\hline Manual Spinal Mobilization $^{\dagger}$ & 22 & 71 \\
\hline Instrumented Myofascial Release & 12 & 39 \\
\hline Stress Reduction/Visualization & 5 & 16 \\
\hline
\end{tabular}

${ }^{*}$ High-velocity, low-amplitude thrust procedures.

${ }^{\dagger}$ Low-velocity, nonthrust procedures.

OIF/CEF = Operation Iraqi Freedom/Operation Enduring Freedom, VHA = Veterans Health Administration. 


\section{Outcomes}

Patients were routinely questioned in order to assess the occurrence of adverse events. Seventeen cases (55\%) reported no adverse events throughout treatment. Of the 14 cases (45\%) reporting adverse events, 8 reported a mild pain increase after one visit only, 4 reported a moderate-to-severe pain increase after one visit only, and 2 reported a moderate-to-severe pain increase after two visits. In all cases of adverse events, the increase in pain self-resolved within 4 to 48 hours.

The group median NRS score at last visit was 4 (mean 3.7, range 0 to 9). The group median change in NRS score was -3 (mean -2.7, range 0 to -6). However, when considered individually, 19 cases (61\%) reported a decrease of 2 or more points on the NRS, whereas 12 cases (39\%) reported no decrease or a decrease of 1 point only. No patient reported an increase in NRS score.

No cases displayed features requiring mandatory consultation to other services. At the completion of care, 14 patients (45\%) reported satisfaction with outcome and were discharged, 11 (35\%) were referred to other services for continued management, and 4 (13\%) reported significant remaining pain but declined other treatment options. Two cases (6\%) were lost to follow-up after the second visit. Of the 11 cases consulted to other services, the most common consultations were to physiatry and mental health.

\section{DISCUSSION}

This study presents the first preliminary data on management of OIF/OEF veterans in a VHA chiropractic clinic. Thirty-one such veterans were identified as receiving services over a 6-month period. Previous investigators have described patient characteristics and service utilization for all patients within a VHA chiropractic clinic [12-13]. Compared with the patients in those studies, the patients in the current study were younger, more likely to have suffered traumatic injury and/or PTSD, and more likely to be female. These differences are expected given the selection of the OIF/OEF patient subpopulation in this work. Patients in the current study were also more likely to complain of thoracic pain. This finding may be explained by differences in the mechanisms of injuries sustained by this group, including prolonged wearing of individual body armor [14].
Most consultations originated in primary care clinics. Other consulting services included those that commonly encounter musculoskeletal complaints, such as physiatry, rheumatology, urgent care, and neurology. This pattern reflects the service agreement and integration processes in place at this facility. Chiropractic clinics in other facilities may have been introduced differently; thus, different consultation patterns may be expected [4].

Patients received standard care as typically delivered at the VACHS chiropractic clinic. In this multimodal, structured, pragmatic approach, therapeutic intervention decisions were based on existing published evidence, the clinician's impression of the given patient, and patient preference. This case-management strategy is consistent with current knowledge; however, neither this nor any other multimodal approach to nonoperative musculoskeletal complaints is an established gold standard.

Treatment duration was determined pragmatically, with no improvement over two to four consecutive visits during the trial typically indicating the end point. Patients who reached resolution of pain (0/10 on the NRS) were discharged. Patients who reported improvement that had reached a plateau yet who were satisfied with this improvement and requested no further follow-up were also discharged.

In cases with minimal or no improvement, no patient exhibited features that would clearly indicate more aggressive follow-up (such as progressive neurological deficit); thus, management was based on subjective pain intensity and functional limitations. Patients reporting persistent symptoms and requesting additional follow-up were referred to another specialty clinic if indicated and/ or to the original consulting provider.

The patient group was heterogeneous in pain complaints: most cases involved low back pain, followed by thoracic pain, and then neck pain. Reported adverse events were mild, transitory, and consistent with previous reports [15]. Overall, 19 cases (61\%) reported a pain decrease that exceeded the threshold for minimally important change [9] after the care delivered in this study. Fourteen cases (45\%) were satisfied with outcomes and required no additional follow-up from other services. This response pattern-reported benefit by some patients but not by others-is not unexpected for two reasons. First, as is known for nonoperative low back pain cases, several treatment options are of demonstrated effectiveness but predicting response for a given patient in advance of treatment is currently not possible [16]. 
Second, the high prevalence of PTSD in this sample may affect outcome.

The presence of comorbid PTSD in patients with somatic pain complaints is well described [17]. PTSD and chronic pain often co-occur and "may interact in such a way as to negatively impact the course of either disorder" [17]. This phenomenon has recently been described in a general population of spinal pain patients at a VHA chiropractic clinic [18].

Whether or not PTSD had any effect on outcome, this study describes patient screening and consultation in the chiropractic clinic. Formal diagnosis of PTSD and subsequent patient compliance with mental health management have been shown to be challenging [19]. Delayed diagnosis of PTSD may occur, since some patients who deny PTSD symptoms at initial screening by primary care and/or mental health providers may subsequently develop-or reach the point to endorse- these symptoms at a later date. Since VHA specialty clinics can encounter such patients, specialty providers managing OIF/OEF veterans may need to be aware of this phenomenon and consider appropriate screening processes.

Overall, these data provide an initial view of chiropractic management of OIF/OEF veterans in one VHA clinic. VHA primary care and specialty providers may consider chiropractic services when managing musculoskeletal conditions in OIF/OEF patients. This report shows that chiropractic management was safe and may be effective in reducing pain in some cases. Additional work is needed to identify the patient subgroup that is most likely to improve after chiropractic management and to maximize the benefit of chiropractic interventions overall. The results presented here can inform follow-up studies with larger sample sizes across multiple sites to identify factors that correlate with effective, efficient case management.

This work has a number of limitations. The data sources are not independent of this study's investigator and thus bias can be introduced. Because of data entry and/or extraction error, the method used to identify OIF/ OEF cases can result in underreporting. No evidence exists that the pragmatic approach used in this clinic is the optimal one for management of these patients. Although most cases already had failed a number of treatment options before consultation, other treatment received during the study period was not considered. Outcome assessment was limited to pain intensity only; functional assessment with validated measures was not performed in every case. Lastly, no follow-up occurred beyond the completion of the treatment trial, so the longterm response to care is not known.

\section{CONCLUSIONS}

This work is the first description of health services delivered to OIF/OEF veterans in a VHA chiropractic clinic. Thirty-one OIF/OEF veterans were seen in a 6-month period, with 19 cases (61\%) reporting a pain decrease above a minimally important threshold. Chiropractic management was safe in these cases, and the results support the hypothesis that chiropractic management may be effective in certain OIF/OEF veterans. A better understanding of the characteristics of these particular patients and the processes of care received in VHA chiropractic clinics is needed to improve the clinical care of these veterans.

\section{ACKNOWLEDGMENTS}

Financial Disclosures: The author has declared that no competing interests exist.

Funding/Support: This material was unfunded at the time of manuscript preparation.

Additional Contributions: Dr. Lisi is now also affiliated with VHA Chiropractic Service, Washington, DC.

Institutional Review: This study was approved by the VACHS Research Committee and Institutional Review Board.

Participant Follow-Up: The author does not plan to inform participants of the publication of this study.

\section{REFERENCES}

1. Veterans Health Administration. VHA Directive 2008-054: Combat veteran health care benefits and copay exemption post-discharge from military service. Washington (DC): Veterans Health Administration; 2008.

2. Analysis of VA health care utilization among U.S. Global War on Terrorism (GWOT) veterans. Washington (DC): VHA Office of Public Health and Environmental Hazards; 2009.

3. Office of Policy and Planning. Analysis of unique veterans utilization of VA benefits \& services. Washington (DC): Office of Policy and Planning, National Center for Veterans Analysis and Statistics (008A3); 2009.

4. Lisi AJ, Goertz C, Lawrence DJ, Satyanarayana P. Characteristics of Veterans Health Administration chiropractors and chiropractic clinics. J Rehabil Res Dev. 2009;46(8):997-1002. 
5. Bronfort G, Haas M, Evans R, Kawchuk G, Dagenais S. Evidence-informed management of chronic low back pain with spinal manipulation and mobilization. Spine J. 2008; 8(1):213-25. [PMID: 18164469]

DOI:10.1016/j.spinee.2007.10.023

6. Hurwitz EL, Carragee EJ, Van der Velde G, Carroll LJ, Nordin M, Guzman J, Peloso PM, Holm LW, Côté P, HoggJohnson S, Cassidy JD, Haldeman S; Bone and Joint Decade 2000-2010 Task Force on Neck Pain and Its Associated Disorders. Treatment of neck pain: Noninvasive interventions: Results of the Bone and Joint Decade 20002010 Task Force on Neck Pain and Its Associated Disorders. Spine (Phila Pa 1976). 2008;33(4 Suppl):S123-52. [PMID: 18204386$]$

7. Cohen SP, Griffith S, Larkin TM, Villena F, Larkin R. Presentation, diagnoses, mechanisms of injury, and treatment of soldiers injured in Operation Iraqi Freedom: An epidemiological study conducted at two military pain management centers. Anesth Analg. 2005;101(4):1098-1103. [PMID: 16192528] DOI:10.1213/01.ane.0000169332.45209.cf

8. Clark ME, Bair MJ, Buckenmaier CC 3rd, Gironda RJ, Walker RL. Pain and combat injuries in soldiers returning from Operations Enduring Freedom and Iraqi Freedom: Implications for research and practice. J Rehabil Res Dev. 2007;44(2):179-94. [PMID: 17551872] DOI:10.1682/JRRD.2006.05.0057

9. Downie WW, Leatham PA, Rhind VM, Wright V, Branco JA, Anderson JA. Studies with pain rating scales. Ann Rheum Dis. 1978;37(4):378-81. [PMID: 686873] DOI:10.1136/ard.37.4.378

10. Farrar JT, Berlin JA, Strom BL. Clinically important changes in acute pain outcome measures: A validation study. J Pain Symptom Manage. 2003;25(5):406-11. [PMID: 12727037] DOI:10.1016/S0885-3924(03)00162-3

11. Prins A, Ouimette P, Kimerling R, Camerond RP, Hugelshofer DS, Shaw-Hegwer J, Thrailkill A, Gusman FD, Sheikh JI. The primary care PTSD screen (PC-PTSD): Development and operating characteristics. Prim Care Psychiatr. 2003;9(1):9-14. Corrigendum in: Prim Care Psychiatry 2004;9(4):151.
12. Dunn AS, Passmore SR. Consultation request patterns, patient characteristics, and utilization of services within a Veterans Affairs medical center chiropractic clinic. Mil Med. 2008;173(6):599-603. [PMID: 18595426]

13. Dunn AS, Towle JJ, McBrearty P, Fleeson SM. Chiropractic consultation requests in the Veterans Affairs Health Care System: Demographic characteristics of the initial 100 patients at the Western New York medical center. J Manipulative Physiol Ther. 2006;29(6):448-54. [PMID: 16904490] DOI:10.1016/j.jmpt.2006.06.002

14. Konitzer LN, Fargo MV, Brininger TL, Lim Reed M. Association between back, neck, and upper extremity musculoskeletal pain and the individual body armor. J Hand Ther. 2008;21(2):143-48. [PMID: 18436136] DOI:10.1197/j.jht.2007.10.017

15. Senstad O, Leboeuf-Yde C, Borchgrevink C. Frequency and characteristics of side effects of spinal manipulative therapy. Spine (Phila Pa 1976). 1997;22(4):435-40.

[PMID: 9055373] DOI:10.1097/00007632-199702150-00017

16. Haldeman S, Dagenais S. A supermarket approach to the evidence-informed management of chronic low back pain. Spine J. 2008;8(1):1-7. [PMID: 18164448] DOI:10.1016/j.spinee.2007.10.009

17. Otis JD, Keane TM, Kerns RD. An examination of the relationship between chronic pain and post-traumatic stress disorder. J Rehabil Res Dev. 2003;40(5):397-405.

[PMID: 15080224]

DOI:10.1682/JRRD.2003.09.0397

18. Dunn AS, Passmore SR, Burke J, Chicoine D. A crosssectional analysis of clinical outcomes following chiropractic care in veterans with and without post-traumatic stress disorder. Mil Med. 2009;174(6):578-83. [PMID: 19585768]

19. Magruder KM, Frueh BC, Knapp RG, Davis L, Hamner MB, Martin RH, Gold PB, Arana GW. Prevalence of posttraumatic stress disorder in Veterans Affairs primary care clinics. Gen Hosp Psychiatry. 2005;27(3):169-79.

[PMID: 15882763] DOI:10.1016/j.genhosppsych.2004.11.001

Submitted for publication July 9, 2009. Accepted in revised form November 6, 2009. 